\title{
The Control Process Effectiveness: Organization Versus Customer
}

Ofer Barkai, The Sami Shamoon College of Engineering, Israel

\begin{abstract}
This research project, which was implemented in an organization whose primary function is providing service (Telecommunication company), studies the scope of the correlation between the quality of service from the customer's point of view (customer survey) and the organization (Telecommunication company systems). The research is important both for economic and scientific reasons. It involves many organizational control units which require significant monetary investments. From a scientific point of view, the research is important because it can shed light on the asymmetrical point of view existing between customers and organizations. Organizations that are service providers place high importance on the quality of service and their image as perceived by their customers. Quality of service is measured through internal control processes and from there is passed on to the staff who are directly involved in customer service. In this study, we focus on a large organization which implements control processes and then provides service to customers. Therefore, the activities of this organization are judged first and foremost on the basis of the service quality provided. The existing internal control processes of the organization, which measure the standard of service provided on the basis of organizational benchmarks are separate from those that measure customer satisfaction. In this project, we analyze the correlation between the outlook of the customer and the results of internal control processes.
\end{abstract}

Key Words: Telecommunication Company; Customers Satisfaction Survey; Internal Control Process; Service Quality

\section{INTRODUCTION}

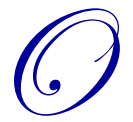

ne of the most important goals of a company is to create disposition toward the company's products and services. The rapid growth of the modern markets, along with the growing demand for quality products and services and the intense competition of our time, have led companies to design their service strategies to achieve this goal. Growing demands for service quality, liability and efficiency became a major consideration in the service strategy design and services operation provided to the costumer (Tervydisa \& Rindzevičius, 2006).

Roth \& Van Der Velde (1991) present a service strategy paradigm which explicitly considers service strategies as a competitive weapon, aimed to better one's company from its competitors. This is crucial, as stated before, in competitive markets. As competition increases, companies strive to differentiate themselves trying to stress their good qualities and uphold their stature as the best in their field.

Urban W. (2009), in his research "Service quality gaps and their role in service enterprises development", suggested that the main management problem, according to research achievements, is the gap between managers' perception of customers' expectation and service specifications existing in organizations. In a service organization, usually more quality gaps might be identified. Identification of specific quality gaps is advantageous from a management point of view.

To a company in a constant competition with numerous competitors, "The Marketing Concept" most important principle is the focus on the customer. That is why it is vital to maintain internal quality of service 
measurements, as once stated by Broadbent - "You can't manage what you can't measure"(Broadbent, 2007). Kaziliūnas (2008) presented the main topics of how to manage quality audit according to the requirements and the new quality management principles of ISO 9001:2000 standards as QA.

Monitoring and control systems in organizations that are service providers are crucial in order to detect decline in the quality of service in real time. Additionally, there are Service Level Agreements (SLA) aimed at maintaining high levels of service quality in which the company undertakes to provide service according to a written contract and incurs fines when promises are not delivered (Fu\&Vahdat, 2002).

Customer surveys are another way to express customers' opinions which are impacted by many factors, including the quality of service and the way the company relates to them. Since the customer is the focal point, it is necessary to be aware of the meaning of customer surveys.

Profitability in the telecommunications market in Israel rose from 33\% in 2007 to $37 \%$ of income in 2009. At that time, the mobile phone market represented about $56 \%$ of the telecommunications market while the landline phone market represented only $14 \%$ of all revenues of the telecommunication market (Gronau et al, 2008; Ministry of Communications, 2012). Since 2011, the regulator opened the market for new companies which eventually lowered the profitability of the sector and made it highly competitive.

Some of the companies in this sector failed to keep the companies' strategy and the customer desires aligned while others used service strategy to increase their customer base.

A similar situation to the one previously presented in the Israeli telecommunication market has been studied in a research about postal service in an Eastern European country, which was conducted by Marković, et al (2011). As a result of the regulator intervention in the postal market, many new companies started providing postal services. Such a tendency poses stringent requirements for the structure and the quality of services, as well as encourages competition.

As we know, the service strategy determined by the company dictates the service quality, which the company examines from time to time in order to improve it.

As mentioned, internal control systems are not the only way to measure service quality; another alternative is through customer surveys.

An example of service quality, as perceived by the customers, can be found in a research conducted by Sawng et al (2011) - an empirical study on the acceptance of innovative technologies and technological and economic development by the consumer, as well as the customer's general satisfaction of the product.

All these required a further examination of the correlation between service quality as the company perceives it, determined by its service strategy and costumer's opinion on the service quality.

This article examines, based on data collected from one of the largest telecommunication companies in Israel, the correlation between the service strategy of the company and the service quality as perceived by the costumer.

On the one hand, the service strategy is measured by examination of how well the company manages to fulfill its service quality goals - the basis of the service strategy. On the other hand, the service quality, as perceived by the costumer, is measured by satisfaction surveys about the company's activity among the customers.

\section{EXISTING ORGANIZATIONAL CONTROL PROCESSES}

In organizations, control activities aimed at ensuring quality of service take place on a monthly basis in order to provide feedback to employees involved in the service system. In service-providing organizations, great importance is placed in tracking the quality of service in order to discover negative changes in real time and provide 
warnings. Service-providing organizations tend to measure quality of service by internal documentation which ensures reliable measurements. In organizations where service quality is measured in this manner a customer survey may be distributed on a quarterly basis in order to gauge customer attitudes. In order to test the reliability of the service quality measurements done internally by the company, a comparison can be made to customers' opinions as presented by this quarterly survey. This study investigates the reliability of the internal control and monitoring mechanisms in comparison with results of customer surveys.

\section{Methodology of Control and Monitoring in the Organization}

The control processes of the organization function separately with regard to internal control mechanisms which measure the quality of service according to the viewpoint of the organization - and to the feeling of the customer.

\section{Internal Control - Service Quality of the Organization}

The quality of service delivered by the organization is measured over a period of time utilizing internal tracking lists which are updated in "real time". These records provide knowledge of what was implemented and how quickly implementation took place, as recorded in the internal computer system. Quality Control records enable the units being monitored to reach conclusions and respond in a timely manner as needed. This has special importance in situations wherein quality of service is a central factor; for example, when business competition is underway.

\section{Control and Monitoring - Service Quality from the Customer's point of view}

In addition to internal control systems, the organization may, as stated before, implement Customer Opinion Surveys concerning the quality of service focusing on parallel issues to those covered in internal systems. For this purpose, surveys can be distributed to customers on an ongoing basis.

In order to understand the customer opinions, the results of the surveys and the internal records of the organization were compared referring to a large Israeli telecommunications company.

For the purpose of the statistical analysis, records of eight years were utilized. Our statistical analysis found only a partial correlation between the varients. As a result, the organization needs to revise its internal control processes.

\section{THE MODEL}

\section{Research Methodologies} parameters:

The analysis of organizational control process efficiency was carried out according to the following

- $\quad$ Review of the Professional Literature on the subject

- Analysis of large organizations' data over a period of eight years, as mentioned above

\section{Review Of Professional Literature}

The review of professional literature reveals several key points that contribute to the understanding of the subject:

- There is a growing worldwide demand for service quality and liability. The service strategy of a company is a key factor to achieve these objectives (Tervydisa \& Rindzevičius, 2006). Additionally, the service strategy can be frequently "weaponized" against the company's competitors. This issue is being discussed in several articles such as one by Roth \& Van Der Velde M. (1991). 
- $\quad$ A full competition market like the Israeli telecommunication market can frequently found worldwide. for example, the postal service in eastern European countries presented in an article by Marković et al. ( 2011), has similar features to the Israeli telecommunication market, such as many competitors in a limited market.

- $\quad$ The service quality of a company is measured by various indices and different measurement tools in order to control the quality of ongoing service, as well as providing SLA service (an improved service product supplied for additional payment). Many studies have dealt with the issue of measuring the service quality, including Kaziliūnas (2008), who focused his research on the control of service quality preformed to comply with ISO 9001 standards, and Sawng et al (2011) that carried out an empirical study on customer satisfaction with products.

- However, even though this is a worldwide phenomenon not limited to the Israeli market nor to the telecommunications market, there is no reference in the professional literature for examination of the possible link between the service quality, dictated by the service strategy of the organization, and the customers' opinions.

\section{Analysis Of A Large Public Sector Organization Records Over Eight Years}

\section{Methodology Of Records Analysis}

Records were gathered for eight years - between 2004 and 2011 - and they were analyzed using two theoretical tests (see Table 1):

- $\quad$ T Test: Using t Test, the article examined the similarity of the results.

The first test analyzed whether there is a difference between the quality of service recorded through internal controls of the organization and the quality of service expressed by the customers. This was performed by one-tail and two-tail test with a confidence level of 0.95 .

- $\quad$ ANOVA F Test: In the event that the results were not similar, a second measurement of correlation between the results was performed.

The ANOVA F test was implemented in order to check the extent of correlation between internal records and the opinions of the customers and was performed with a confidence level of 0.95 . The companies were divided to three distinct groups based on annual pay for service: 1) large companies and factories whose annual pay to the telecommunications company exceeds $\$ 200,000,2)$ medium-sized customers that pay the company between $\$ 20,000$ and $\$ 199,999$ every year, and 3) regular customers who annually pay less than $\$ 19,999$.

The model that was tested in the research expresses a connection between two statements - the service quality standards internally measured, which is the non-dependent variable, and the service quality, as measured through customer surveys, which is the dependent variable.

$$
C S i=f(S i)(1)
$$

where

$\mathrm{CSi}=$ the Quality of Service according to results of the Customer Survey

$\mathrm{Si}=$ the Quality of Service according to results of the internal control processes

Statistical Analysis = Two theories were analyzed in the framework of the research

\section{RESULTS}

\section{Results Of The Professional Literature Review}

As stated before, the subject, despite his importance, was not investigated in the past. 


\section{Summary Of Statistical Analysis Results}

Thirty-two observations were carried out over a period of eight years; the results are presented in Table 1 .

Table 1 - Summary Of Results Of Statistical Analysis Of The Records

\begin{tabular}{|c|c|c|c|c|}
\hline & \multicolumn{4}{|c|}{ Type of Statistical Analysis } \\
\hline \multirow[t]{2}{*}{ Criteria } & \multicolumn{2}{|c|}{$\begin{array}{l}\text { ANOVA F- test } \\
\text { Correlation analysis to examine Relation } \\
\text { between the variables } \\
\mathrm{H}_{0}: \rho=0 \\
\mathrm{H}_{1}: \rho>0 \\
\text { Decision criteria: } \mathrm{H}_{0} \text { will be rejected if the } \mathrm{P} \\
\text { value less than }-0.05\end{array}$} & \multicolumn{2}{|c|}{$\begin{array}{l}\text { t. - Test } \\
\mathrm{t}-\text { Test to examine differences between } \\
\text { the variables } \\
\mathrm{H}_{0}: \mu_{\mathrm{x}}=\mu_{\mathrm{y}} \\
\mathrm{H}_{1}: \mu_{\mathrm{x}}>\mu_{\mathrm{y}} \quad \text { One- Tailed Test } \\
\mathrm{H}_{2}: \mu_{\mathrm{x}} \neq \mu_{\mathrm{y}} \quad \text { Two- Tailed Test } \\
\text { Decision criteria: } \mathrm{H}_{0} \text { will be rejected if } \\
\text { the } \mathrm{P} \text { value less than }-0.05\end{array}$} \\
\hline & Pvalue & Decision & Pvalue & Decision \\
\hline \multirow{2}{*}{$\begin{array}{l}\text { Internal Quality of Service vs. } \\
\text { quality of service -survey - } \\
\text { Large business clients }\end{array}$} & \multirow[t]{2}{*}{0.865451} & \multirow[t]{2}{*}{$\mathrm{H}_{0}$ will be accepted } & $\begin{array}{c}\text { One- Tailed Test } \\
1.06 \times 10^{-10}\end{array}$ & $\mathrm{H}_{0}$ will be rejected \\
\hline & & & $\begin{array}{c}\text { Two- Tailed Test } \\
2.13 \times 10^{-10}\end{array}$ & $\mathrm{H}_{0}$ will be rejected \\
\hline \multirow{2}{*}{$\begin{array}{l}\text { Internal Quality of Service vs. } \\
\text { quality of service -survey for } \\
\text { medium sized clients }\end{array}$} & \multirow[t]{2}{*}{0.865451} & \multirow[t]{2}{*}{$\mathrm{H}_{0}$ will be accepted } & $\begin{array}{c}\text { One- Tailed Test } \\
1.06 \times 10^{-10}\end{array}$ & $\mathrm{H}_{0}$ will be rejected \\
\hline & & & $\begin{array}{c}\text { Two- Tailed Test } \\
2.13 \times 10^{-10}\end{array}$ & $\mathrm{H}_{0}$ will be rejected \\
\hline \multirow{2}{*}{$\begin{array}{l}\text { Internal Quality of Service vs. } \\
\text { quality of service -survey for } \\
\text { small sized clients }\end{array}$} & \multirow[t]{2}{*}{0.2504} & \multirow[t]{2}{*}{$\mathrm{H}_{0}$ will be accepted } & $\begin{array}{c}\text { One- Tailed Test } \\
2.5 \times 10^{-13}\end{array}$ & $\mathrm{H}_{0}$ will be rejected \\
\hline & & & $\begin{array}{c}\text { Two- Tailed Test } \\
5.17 \times 10^{-13}\end{array}$ & $\mathrm{H}_{0}$ will be rejected \\
\hline
\end{tabular}

As can be seen in Table 1, the calculated p-values for the T-test in all three sectors were below the threshold chosen for statistical significance $(\mathrm{P}<0.05)$, so the null hypothesis is rejected (Highest $\mathrm{P}$ value was $\left.1.06 \times 10^{-10}\right)$. The $\mathrm{F}$ test presents similar results. All three P-values were above the threshold chosen for statistical significance $(\mathrm{P}>0.05)$, so the null hypothesis was Accepted (Lowest $\mathrm{P}$ value was 0.2504$)$.

Figure 1 presents quarterly results over a period of eight years. As can be seen in the figure, the quality of service measured internally over eight years is considerably higher than the quality of service as measured by customers' surveys.

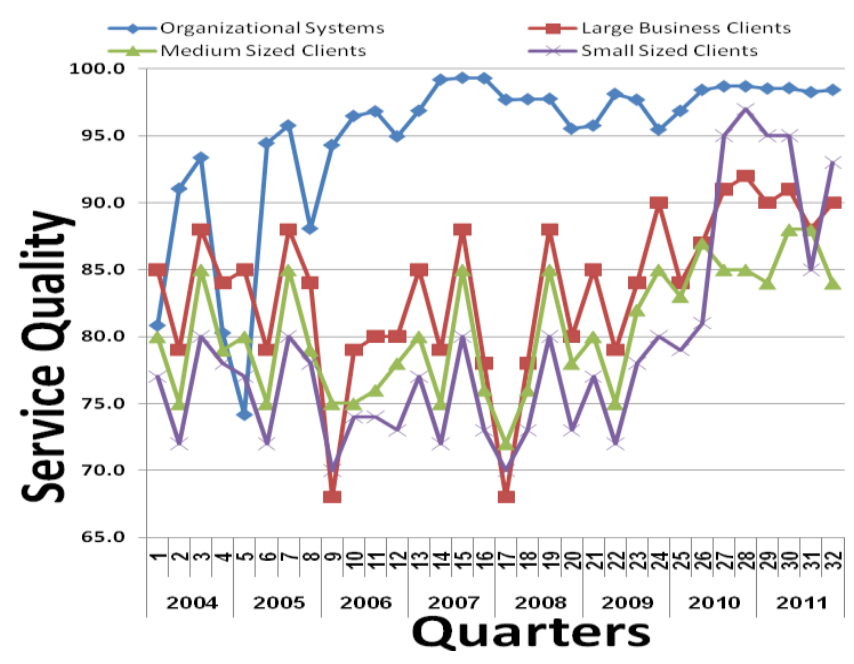


Figure 1: Comparisons Of Internally Measured Quality Of Service Vs. The Position Of Customers MSE):

In Figures 2, 3, and 4, forecasts were built on the basis of the trend as a linear regression (according to

For Large Customers,

(5) $\mathrm{CSi}=0.2639 \mathrm{Si}+79.2\left(\mathrm{R}^{2}=0.1706\right)$

For Medium size Customers,

(6) $\mathrm{CSI}=0.2549 \mathrm{Si}+76.26\left(\mathrm{R}^{2}=0.2679\right)$

For Small Customers,

(7) $\mathrm{CSI}=0.529 \mathrm{Si}+70.3\left(\mathrm{R}^{2}=0.4009\right)$

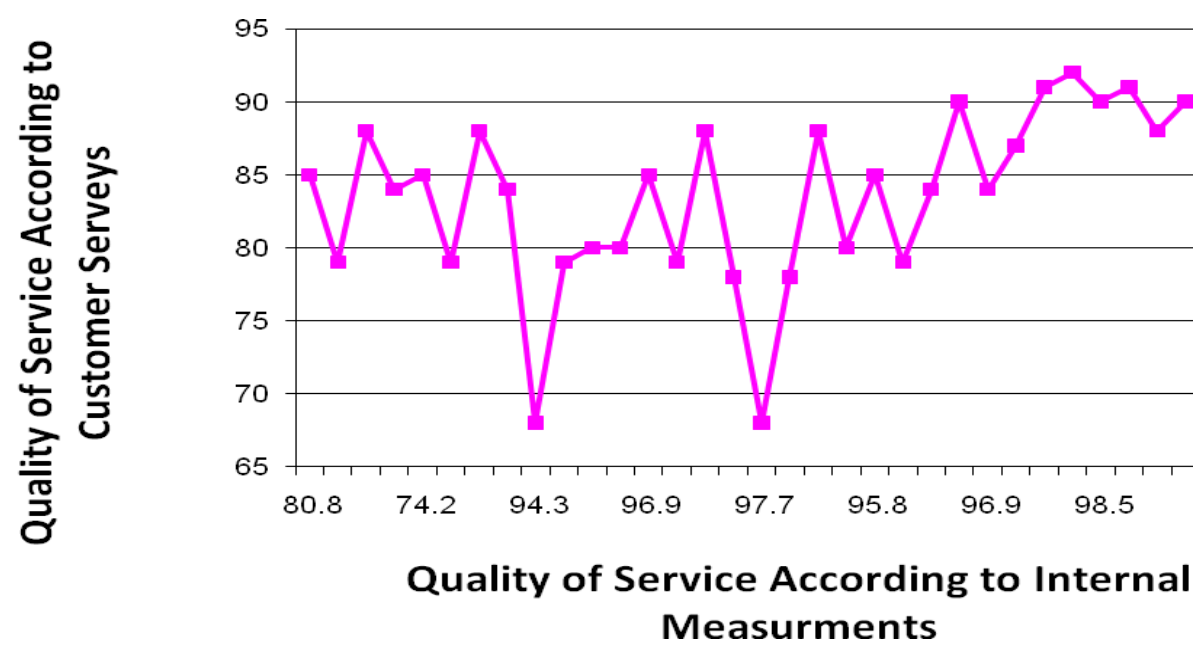

Figure 2: Quality Of Service For A Large Customer As A Function Of Internally Measured Service Quality

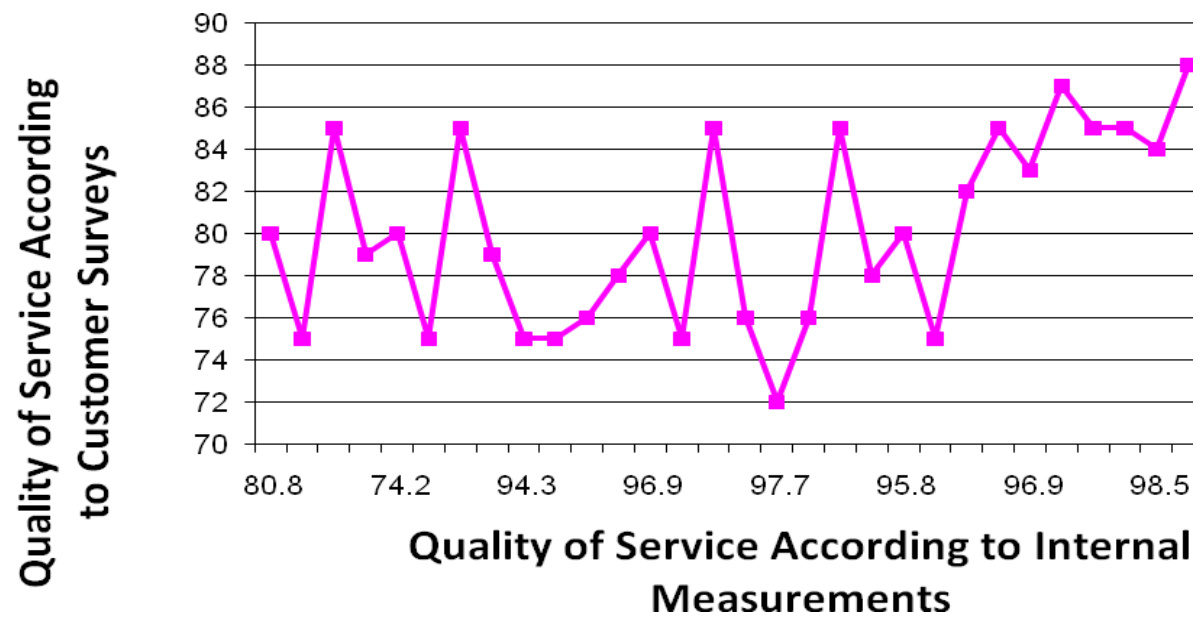

Figure 3: Quality Of Service For A Medium Sized Customer As A Function Of Internally Measured Service Quality 


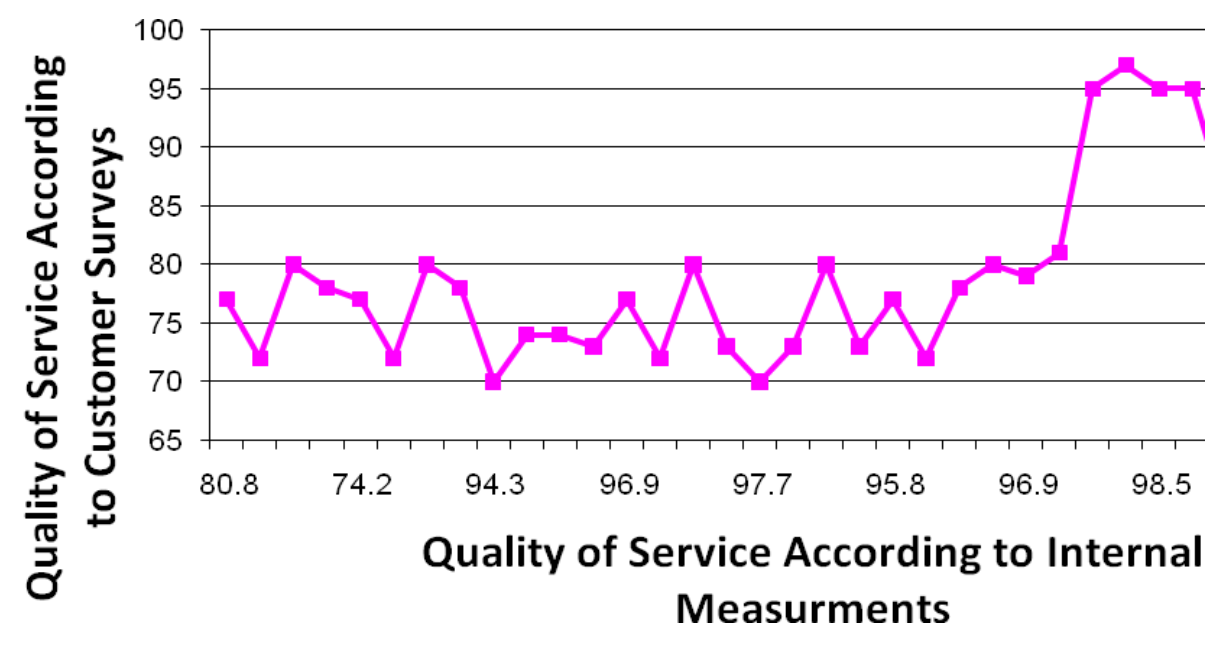

Figure 4: Quality Of Service For A Small Customer As A Function Of Internally Measured Service Quality

\section{DISCUSSION OF CONCLUSIONS AND RECOMMENDATIONS}

The company's service concept was based on several principles:

- Marketing concept whereby the customer is in the center and the service is performed by examining the desires of the customers

- $\quad$ Establishing a company service treaty comprised of measurable goals

- SWOT Analysis that examines the opportunities and threats in the telecommunication market as well as the strengths and weaknesses of the company

The article examines whether there is a correlation between the organization's service strategies and the customers' needs which were expressed by customers' surveys. The findings indicate that there is a contradiction between the customer service surveys and the service strategy of the telecommunications company as no significant correlation was found (Table 1). This negatively impacts the ability of the internal system to be proactive and warn about problems. Additionally, this compromises the ability to use the internal system as a basis for creating "quality of service treaty".

A study of customer service surveys vs. internal controls quality of service graph (see Figures 2, 3, and 4) shows that there is a trend of slight increase in service quality as shown in customer surveys in comparison with organizational data that was measured. It may be that this increase is the result of feedback received by the internal functionaries of the organization.

It should be noted that during 2009 and 2010, the organization publicized a "Quality of service Treaty". The launching of the treaty included implementation activities in which all of the workers were involved. During these years, changes were made in the organizational structure which enabled them to focus on customer service. During this period, benchmarks were set for quality of service and service agreements were signed with companies (customers).

However, as mentioned previously, the correlation between the internal records and the customer surveys was very low even after the treaty was published. The quality of service rose and yet the measuring procedures were inefficient to recognize this change. 
Thus, internal quality of service system should be revised to correlate to the customer's surveys. Such correlation is needed to turn the internal quality of service system into a purposeful and meaningful prediction tool.

Until such revision is made, the only solution for short time analysis of service quality is a monthly analysis of Customers Surveys despite the high cost and labor involved in such an activity.

\section{AUTHOR INFORMATION}

Ofer Barkai (Ph.D.) is a Lecturer in the Department of Industrial and Management Engineering at SCE College of Engineering. In addition he has 27 years of industrial experience. He specializes in wage and compensation strategies at the organizational and managerial levels, Compensation schemes, Sectorial compensation, payment methods and service quality in organizations. Dr. Barkai is a member of the conference committee of The European Conference on Information Management and Evaluation (ECIME), as well as a Member of the Managing Committee of the Israeli Industrial Engineering and Management Engineers' Bureau. E-mail: ofer@sce.ac.il

\section{REFERENCES}

1. Broadbent J., (2007), If you can't measure it how can you manage it, Research Papers from the School of Business and Social Sciences, School of Business and Social Sciences, pp. 1-11.

2. $\quad$ Fu Y., Vahdat A.,(2002), Service Level Agreement Based Distributed Resource Allocation for Streaming Hosting Systems, Proceedings of the Seventh International Workshop, Web Content Caching and Distribution (WCW).

3. Gronau R., Mordechai M. \& Rubinstein N.,(2008), The Report of the Committee for Detailed Recommendations Regarding Policy and Competition Rules in the Telecommunications Industry in Israel 2008 - Report Adoption, Changes and Emphases, Minister of Communications, Israel.

4. Kaziliūnas, A. (2008), Problems of auditing using quality management systems for sustainable development of organizations, Technological and Economic Development of Economy, Volume 14, Issue 1, pp.64-75.

5. Marković, D. Grgurović B. \& Štrbac S., ( 2011), The Use of Spatial Data for Segmentation of the Postal Service Market, Technological and Economic Development of Economy, Volume 17, Issue 1, pages 87100.

6. Ministery of Communications, (2012), Telecommunications in Israel 2012, Available at http://www.moc.gov.il/sip_storage/FILES/5/605.pdf, Israel.

7. Roth A. V.\& Van Der Velde M.,(1991), Operations as marketing: A competitive service strategy, Journal of Operations Management, Volume 10, Issue 3, pp. 303-328.

8. $\quad$ Sawng Y, Kim S., Lee J. \& Oh Y.S., (2011), Mobile Service Usage Behavior in Korea: An Empirical Study on Consumer Acceptance of Innovative Technologies, Technological and Economic Development of Economy, Volume 17, Issue 1, pages 151-173.

9. Tervydisa P. \& Rindzevičius R., (2006), Investigation of batch data flow transmission parameters, Technological and Economic Development of Economy, Volume 12, Issue 4, pages 327-333.

10. Urban W., (2009) Service quality gaps and their role in service enterprises development, Technological and Economic Development of Economy, Volume 15, Issue 4, pp. 631-645. 